\title{
Developing an African Research Network and Research Agenda on Work Family Interface
}

\author{
A journal article submitted for consideration by \\ Community, Work \& Family
}

$\underline{\text { Authors: }}$

Zitha Mokomane ${ }^{1}$ (Corresponding author)

Sintechè van der Merwe ${ }^{2}$

Mariam Seedat Khan ${ }^{3}$

Ameeta Jaga $^{4}$

Lisa Dancaster ${ }^{5}$

Address:

Department of Sociology

University of Pretoria

Private Bag X20

Hatfield, 0028

Pretoria, Republic of South Africa

Tel: (+27) 4203744

Email: zitha.mokomane@up.ac.za

1. Zitha Mokomane is an Associate professor in the Department of Sociology at the University of Pretoria, South Africa. Her research interests include work-family balance, social protection, and family demography.

2. Sintechè van der Merwe is a lecturer in the Department of Sociology at the University of South Africa and a PhD candidate at the University of Johannesburg, Lecturer at the Department of Sociology, University of South Africa. Her research interests are gender studies.

3. Mariam Seedat-Khan is a senior lecturer in the Department of Sociology at the University of KwaZulu-Natal, South Africa. Her research interests are gender, family, identity, work life balance, domestic work and socialisation.

4. Ameeta Jaga is a senior lecturer in the School of Management studies at the University of Cape Town, South Africa. Her research interests include the work-family interface in relation to culture and gender, and breastfeeding at work.

5. Lisa Dancaster is a post-doctoral fellow at the University of KwaZulu Natal in South Africa. Her research interests include work-care integration and parental leave policies.

\section{Acknowledgements}

The support of the DST-NRF Centre of Excellence in Human Development under Grant No. OPP20150008 is acknowledged. Opinions expressed and conclusions arrived at, are those of the authors and cannot be attributed to the $\mathrm{CoE}$ in Human Development. 


\begin{abstract}
In this article we aim to provide a narrative of the critical engagement on work-family issues in Africa that took place during the inaugural workshop of the African Research Network on Work-Family held at the University of Pretoria, South Africa in September 2015. The interdisciplinary experts at the workshop agreed that with funding and appropriate local data, the Network has the potential to make a substantial contribution to strengthening and amplifying African voices in the global work-family discourse, which is currently dominated by research findings and literature from the Global North. A future research agenda was also proposed.
\end{abstract}

\title{
KEYWORDS
}

Work-family; Africa; research network; Global South

\section{Introduction}

Many countries in both the Global South and North are experiencing various socioeconomic and demographic transformations that have the potential to negatively affect the work-family balance of employees in those countries. Changes such as aging populations, changes in family structure and the labour market, increased migration and urbanisation, and, in many African countries, high prevalence of HIV and AIDS are well-documented (Damon, 2010; Mokomane, 2014). Despite this, much of the research on the interaction between work and family continues to focus on countries in North America, Europe, and advanced Asian and Pacific economies (Heymann et al, 2004). While, as Heymann and colleagues assert, studies in these countries have yielded important findings, their limited geographic coverage means that there remains a "disparate and fractured understanding of the dynamic interplay between work and family for those who live and work beyond the borders [of countries in the Global North] as conceptualisations, methods and operationalisations are often inappropriate to cultures in the South (Shaffer et al, 2011:222). As a result there has been increasing calls for more cross-cultural research on work-family interface (see for example, Aycan, 2005; Poelmans et al, 2005; O'Brien, 2012) with the basic thesis being that by excluding Asian, African and Latin American countries, the current work-family research is ignoring a range of global variations (Mapedzahama, 2014).

The importance of unearthing and sharing cross-cultural findings in this broad subject has also found its way into international policy documents. For example, the United Nations Economic and Social Council's Resolution 2011/29 on the "Preparations for an observance of the twentieth anniversary of the International Year of the Family" encouraged Member States to develop and implement appropriate policies to address, among other things, workfamily balance and share good practices in this area. In Africa the Common Position on the Family (African Union, 2012) encourages its Member States to "promote work-family balance by putting in place context-specific mechanisms and policies to facilitate the balancing of work and family responsibilities". 
Despite such calls, African research in the broad area of the work-family interface remains scarce and rudimentary. An exploratory review of journal articles published between 2000 and 2011 on work-family issues in Africa (Mokomane \& Chilwane, 2014) found that much of the literature emanates from studies conducted in two countries: South Africa and Nigeria. It also emerged that an overwhelming majority of the studies used small cross-sectional samples to quantitatively explore mainly two broad areas, namely gender differences in experiences of work-family conflict, and experiences of the conflict in specific occupations and industries. To this end, the contextually salient factors shaping the work-family experiences of people in Africa are not clearly understood as is the extent to which workfamily conflict may be affecting the well-being of employees and their families, and the productivity of employers on the continent.

The dissemination of African research on work-family interface is also limited to few stakeholders on the continent. Mokomane and Chilwane's review, for example, revealed that most of the African research findings are published in local South African and Nigerian journals; extremely few appeared in core journals that demonstrate a commitment to workfamily issues and through which authors are likely to reach both researchers and policymakers in the field (Drago \& Kasihain, 2003:50). On the other hand, as Njuguna and Itegi (2013) have pointed out, even when African research is accepted and published in international journals the costs of access as well as poor technological infrastructure often makes it inaccessible to local researchers, policymakers and other stakeholders who may need it the most. Two of the most prominent international academic research networks in the field (the US-based Work and Family Researchers Network or WFRN and the Europeanbased International Network on Parental Leave Policy and Research or INPLPR) also rarely have African research on their agendas. For example at the inaugural WFRN conference in 2010, only six out of more than 200 papers presented were on African countries while at the 2012 conference 13 papers on Africa were presented again out of more than 200 papers. At the 2016 conference only 10 out of more than 400 papers and two posters out of more than 60 were presented on African countries. The website of the INPLPR, on the other hand, states that "the network has members from 35 countries mostly in Europe, but some from beyond, including Australia, Canada and the United States". The participation of African researchers in the network is therefore extremely minimal, if any.

It was with this background that in September 2015 a group of academics, researchers and policymakers with an interest in work-family issues in Africa met at the University of Pretoria in South Africa for a one-day inaugural workshop which provided participants with platform to: share information on existing work-family research in Africa and generate ideas for future collaborative work; identify data needs, expertise, and funding opportunities to further address the issue; establish the African Research Network on Work and Family (ARNWF); and discuss links between the Network and other relevant initiatives. The 
workshop, which was funded by the South African National Research Foundation and Department of Science and Technology's Centre of Excellence on Human Development, drew participants from Australia, Kenya, Nigeria, the United Kingdom, and South Africa.

The Network is not, in any way meant to compete with existing international networks on the subject or, as Jacobs (2013) warned, to perpetuate the myriad of lines of demarcation based on disciplines, research styles, and national borders that could divide and divert the global work-family research community. Rather, the impetus for its establishment was to provide a platform that can - within the context of the limiting research environment in Africa (Njuguna \& Itegi 2013) - complement individual efforts of members and that of portals established by other networks and regional initiatives in order to produce and share the evidence base that policymakers on the continent can use to pro-actively address Africa's work-family challenges and replicate successes.

This paper presents a narrative of the critical engagement that took place during the workshop. The paper is begins with a summary of the proceedings of the workshop. The proposed future research agenda for the Network which emanated from the discussions during the workshop is then presented before the paper concludes by highlighting the key tenets of the Network.

\section{Summary of the workshop proceedings}

In addition to the introductory and concluding sessions, the core discussions of the workshop were held in three main sessions as shown in Table 1 and as discussed below.

Table 1. Summary of workshop sessions

\begin{tabular}{|c|c|c|}
\hline Session & Title of paper/contribution & Author \\
\hline Setting the stage & $\begin{array}{l}\text { Work-family interface in sub-Saharan Africa: } \\
\text { Challenges \& Responses } \\
\text { African voices in the work-family discourse } \\
\text { Discussant }\end{array}$ & $\begin{array}{l}\text { Zitha Mokomane, University of Pretoria, } \\
\text { South Africa } \\
\text { Samuel Aryee, King's College, London, UK } \\
\text { Marian Baird, University of Sydney, } \\
\text { Australia }\end{array}$ \\
\hline Tales from the field & 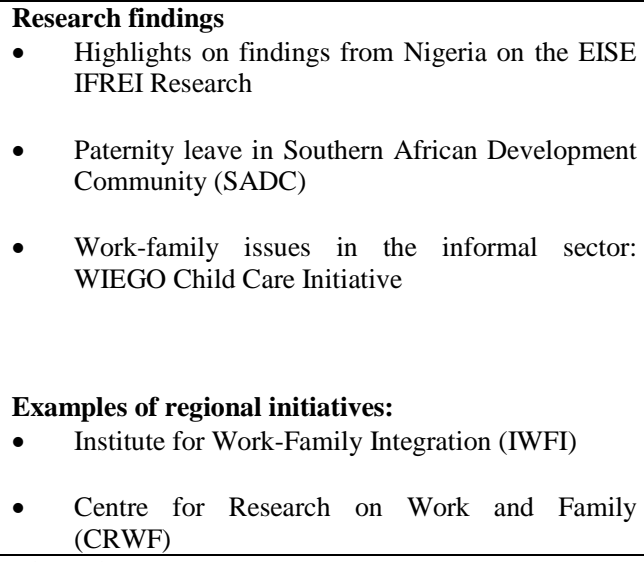 & $\begin{array}{l}\text { Chantal Epie, Pan-Atlantic University, } \\
\text { Lagos, Nigeria. } \\
\text { Lisa Dancaster, University of KwaZulu } \\
\text { Natal, Durban South Africa } \\
\text { Laura Alfers, Women in Informal } \\
\text { Employment: Globalizing and Organizing } \\
\text { (WIEGO), Durban, South Africa } \\
\text { Regina Bazuaye, IWFI, Lagos, Nigeria } \\
\text { Irene Kinuthia, CRWF, Nairobi, Kenya }\end{array}$ \\
\hline Roundtable discussion & $\begin{array}{l}\text { Discussion on: } \\
\text { - } \quad \text { Key work-family issues in Africa. } \\
\text { - } \quad \text { Resources needed to address the identified issues. }\end{array}$ & $\begin{array}{l}\text { Led by Chantal Epie, } \\
\text { University, Lagos, Nigeria. }\end{array}$ \\
\hline
\end{tabular}




\section{Session 1: Setting the stage}

The first main session set the stage for the rest of the workshop through two presentations by Zitha Mokomane and Samuel Aryee. Both presenters illustrated the reality of work-family challenges and the limited workplace and policy support for working caregivers in Africa through the sharing of personal experiences and anecdotal evidence. It was evident from the presentations that while African workers experience similar everyday work-family realities with their counterparts in the Global North, work-family issues do not seem to be perceived as a problem in many countries of the continent. Similar to what Kusakabe (2006) observed in Thailand, family care responsibilities in Africa are not placed on the same pedestal as, say pay and job security. Overall, workplaces and conditions continue to be structured around the assumption that all workers have a source of unpaid labour to care for their families and, as Dancaster (2008:24) noted, "the notion of the ideal worker as essentially male and free of domestic responsibilities still permeates the thinking of many employers". From the presentations it was clear that the following statement could as well explain the prevailing situation in contemporary Africa:

The lack of collective measures and support for balancing paid work and family responsibilities constrains many households to turn to 'individual reconciliation strategies', often with adverse consequences to families' wellbeing and decent work objectives. This situation hits poor and vulnerable families the hardest, as they have the weakest economic capacity to purchase goods (processed foods, labour saving devices) or services (private childcare, health services for the ill, domestic help) that can free up time for paid work (International Labour Organisation, 2010:4)

In discussing the two presentations, Marian Baird drew from her expertise in the field and shared her insight on contemporary issues of concern around the broad subject of workfamily interface and how these are relevant for Africa. She further argued that there is sufficient African material available on the subject, but the main question is how it can be effectively analysed, disseminated, and utilised in policy development. Based on her experience as the director of a similar research network (the Australian-based Women and Work Research Group) she also offered ideas on different models for further developing and maintaining the ARNWF.

The overall 'take-home' message from this session was that the diverse nature of what constitutes a family and work in contemporary Africa demands that scholars on the continent and the diaspora place these issues at the centre of their work so as to provide an African voice in the development of models and coping strategies that can enhance work-family balance of employees in Africa.

\section{Session 2: Tales from the field}

This second session presented examples of current work-family research on the continent. The first presentation by Chantal Epie was an overview of the salient findings from the IESE 
Family Responsible Employer Index (IFREI) conducted between 2010 and 2011 in Nigeria. The index provides a national versus global comparison on the extent to which companies are perceived by their employees as having a family-responsible culture (Las Heras et al, 2014). The presentation showed that 59\% of employees in Nigeria perceived that their work environment occasionally hindered work-family balance while $15 \%$ though that the work environment did so systematically. Only $5 \%$ perceived that their environment systematically facilitated work-family balance while $22 \%$ perceived that their environment occasionally did so. It was explained that these results partly reflect the limited opportunities in Nigerian companies to participate in part-time work or other flexible work practices such as compressed work weeks, flexible working hours, or tele-commuting.

With regard to the availability of family-responsible support in the workplace, the results from Nigeria showed limited formal support as reflected in the absence of legislated minimum maternity or paternity leave benefits for employees. The study results, for example, showed that only $21 \%$ of women had access to maternity leave benefits. Access to paternity leave was also low at $9 \%$. By the same token, Nigerian employees reported limited informal support (emotional and instrumental support) from their supervisors for managing their work and family demands.

The second presentation by Lisa Dancaster drew from a recent study that investigated legislative provisions on leave for working fathers in the Southern African Development (SADC) region (Dancaster \& Cohen, 2015). The study found that paternity, parental, and 'other' leave for fathers in the region were either non-existent or offered to a very minimal extent. It was shown that six of the 15 SADC countries offer no leave of any kind for fathers to attend to the birth of their children and only three countries offer paternity leave as a specific entitlement for male employees. The balance of SADC member countries offers a limited form of entitlement in terms of a general, multi-purpose leave provision. An argument was made that this type of leave is a weak form in that it is not reserved for fathers only, it is not exclusively demarcated for leave for the purposes of the birth of a child, and it is often of limited duration. In some countries there are also restrictive qualifications on use of this leave. For instance in South Africa employees can only take this leave if they have been in employment for at least four months and provided that they are employed for at least four days a week ${ }^{1}$.

In the third presentation, Laura Alfers shared the key highlights of a child care initiative started in 2014 by WIEGO (Women in Informal Employment: Globalizing and Organizing). WIEGO is a global network focused on securing livelihoods and improving the status of the working poor, particularly women in the informal sector (WIEGO, 2015). Although child

\footnotetext{
${ }^{1}$ Sec 27(1), Basic Conditions of Employment Act (No. 75 of 1997).
} 
care needs are important both for steering women toward informal employment, and for constraining their income earning activities as informal economy workers (Cassirer \& Addati, 2007:1), this presentation showed that child care services in the informal sector are relatively ignored in major development policy spaces in Africa. Overall, child care among informal sector workers is perceived as a "family issue" and something that women "just" have to deal with.

This second main session also included the sharing of experiences from two regional workfamily initiatives: the Institute for Work and Family Integration (IWFI) in Lagos, Nigeria and the Centre for Research on Work and Family (CRWF) in Nairobi, Kenya. The presentations, made by Regina Bazuaye and Irene Kinuthia respectively, illuminated the successes and challenges of work-family initiatives on the continent. All in all, it was revealed that while the work-family interface is slowly becoming part of the rhetoric in government circles, the "business case" for facilitating employees' work-family balance is still to be fully appreciated by both corporate and public organisations in Africa. As a result funding for initiatives such as IWFI and CRWF remains one of their main challenges. Consistent with what Njuguna and Itegi (2013) noted with regard to challenges of institutions of higher education in Africa, the resultant financial constraints affect virtually all aspects of the initiatives: their operations, processes, missions, as well as the integrity and quality of their activities and outputs.

It was evident from the presentations in this session that another key impediment to rigorous and comparative work-family research in Africa is the paucity and/or incompleteness of appropriate data. Thus the general consensus in the discussion that followed the presentations was that, to gain a nuanced understanding of work-family issues in the African context, future research should aim to integrate emic and etic research designs. It was argued, for example, that interpretive grounded theory could be used to deepen our understanding of novel work-family issues on the continent. More qualitative and mixed-method work-family research were also identified as having the potential to elucidate the meaning of work and family in distinct African contexts, and to elicit culturally relevant constructs that may otherwise not be reflected in existing Anglo-based work-family models (Shaffer et al., 2011).

\section{Session 3: Roundtable discussion}

Led by Chantal Epie, the third session was a roundtable discussion which weaved together the key considerations of the previous sessions through an open and critical engagement aimed at identifying important work-family issues in Africa and resources needed to address the issues. In terms of the latter, the discussion reiterated that financial and data constraints were a major impediment to work-family research in Africa. 
Regarding key work-family issues, the general consensus was that many of the critical questions needed to understand the work-family dimensions in Africa remain unanswered. In line with Waldfogel and McLanahan (2011:6) such questions relate, among others, to the share of employees that have family care responsibilities; the types of family members that require care; the extent to which work hours and conditions are compatible with workers' ability to meet family responsibilities; the extent to which employees can adjust their employment to meet family needs; the consequences, both at the workplace and in the family, of work-family conflict; the business case for providing employees with more flexibility; the policy options that might enhance work-family balance; the roles that employers and government play; and lessons that other countries offer.

The session concluded with the setting of an agenda that the Network and its members could focus on - in terms of research, collaborations, and funding proposals - in the medium to long terms. Taking cognisance of the identified financial constraints, it was agreed that Network members should, among other things, embark on developing joint funding proposals for collaborative research projects both within and across countries; undertake collaborative and comparative research using secondary data sets across themes, institutions and countries; and create a platform for an engagement with international and regional organisations such as the International Labour Organisation, the African Union Commission, regional economic communities etc.

It terms of addressing the key unanswered questions discussed above, it was agreed that a systematic literature review to assess the state of African work-family research and to identify gaps will be undertaken in the short term as a "proof-of-concept" to guide the focus of the Network's short to medium term activities and the research agenda which is presented below.

\section{Proposed future research agenda}

It was agreed that the following issues and questions - presented herein in no particular order of priority - are among those that need to be explored in the short to medium terms:

The conceptualisation of the family in Africa. While there is little doubt that family structure is rapidly changing on the continent, the specific dimension of this transformation is not clearly understood. To this end, research is needed to assess the types and patterns of families in contemporary African societies, the cultural and legal contexts of these families, as well as the trends and factors affecting family development so as to establish how African family rituals and routines interact with workplace demands.

The extent and dimensions of work-family conflict in Africa. To the extent that there is currently little evidence regarding what determines work burdens in Global South countries, 
the extent to which African workers of diverse social and cultural backgrounds perceive their work-family fit, that is, how well have they been able to integrate paid work and family life (Hill et al, 2003) is worthy of study. It was thus agreed that in-depth qualitative studies should be conducted to explore how family and work circumstances influence work burdens experienced by African workers, the sources and types of work family-conflict experienced by different types of workers on the continent, and their capacity to cope with it (Blin, 2008).

The role of fathers. Caution was made for research to not just focus on needs of mothers as carers of children but to also explore the work-family challenges and needs of fathers. This was against the background of evidence showing that efforts to encourage shared parenting and measures to increase the role of fathers in caregiving are virtually non-existent in much of Africa as reflected in the absence of legislated paternity leave or recognition of genderneutral leave arrangements such as parental leave in most countries of the continent.

Care needs of older people. Further consensus was that many African countries share the care concerns of an increasing elderly population with countries in the Global North. Thus the study of the vast difference between the African and Western contexts in terms of the provision of social security and social welfare programmes for older people as well as addressing the care needs of older people and their carers was identified as another critical area of future research in Africa.

The impact of HIV and AIDS. It was further highlighted that the extent to which HIV and AIDS affects work-family dynamics in Africa and contributes to the crisis of care in many countries on the continent is worthy of study, particularly against the background of a large body of research that has highlighted the difficult conditions under which care is provided in these circumstances, and the consequences in terms of the emotional, physical and financial wellbeing of the carers who also have work responsibilities.

Workers in the informal sector. It was further noted that many African countries have labour markets with a large and growing informal sector where incomes are low and workers receive little, if any, recognition in government policy and in the way of social protection. The combination of work and care in this context is particularly difficult given the lack of access to policy measures that support the combination of work and family care responsibilities. Thus the need to understand the work-family challenges of workers in the informal sector who make up about $80 \%$ of the labour force in Africa (African Development Bank, 2013) was underscored.

Childcare dynamics. The need to understand the overall childcare aspects for parents working in both the formal and informal sectors was also underscored as were studies to 
examine the impact, on children, of common coping strategies for childcare, such as the employment of domestic workers and use of family members, particularly older siblings.

Limited legislative support. The minimal provision of policies, programmes, and services from government to support work-family integration was identified as a distinguishing feature of most African countries that was worthy of in-depth research. Overall, legislation on work-family provisions such as leave to attend to care concerns and the right to request flexible working arrangements for the purposes of care are either non-existent or only minimally covered in almost all African countries. This gap provide a potential avenue for research within the Network.

The role of the employers in the provision of work-care arrangements. In line with an assertion by Mokomane (2009), the roundtable discussions revealed that increased job insecurity in the context of slow economic growth and high unemployment defines many labour markets in Africa. The spillover effect of this for work-family issues means that the fear of unemployment has resulted in an ethic of long working hours that are distinctly family-unfriendly and conducive to elevated stress levels among workers. To this end, it was agreed that further studies on employer involvement in work-family arrangements is worthwhile.

\section{Conclusion}

The formal inauguration of the Network took place during the fourth Session led by Samuel Aryee where the importance of forming a network to pursue the foregoing proposed research agenda and other activities to facilitate Africa-focused scholarship and research collaboration on work and family issues was reiterated by all participants. A consensus was reached that the ARNWF will be a not-for-profit alliance of academic, research, and policy stakeholders who have an interest on work-family issues in Africa. The objectives of the Network were set as follows:

1. To provide a platform for work-family scholars and research centres in Africa and beyond to collaborate in order to produce the evidence base for policymakers in the continent to pro-actively address Africa's work-family challenges.

2. To promote and disseminate the work of network members though a shared knowledge platform so as to complement individual efforts of members and portals established by other networks and regional initiatives on the subject.

3. To create a platform for an engagement with international and regional development agencies and organisations to ensure that they draw on African scholars and institutions for work-family research and analysis.

4. To create mechanisms for members to collaborate on comparative research on a variety of research questions on the subject 
Other agreed aspects of the Network included short, medium and long term activities as well as modalities for operation; member involvement; and administration of the Network. It is envisaged that the achievement of the above objectives and the effective implementation of the identified modalities will lead to the clarification in terms of: (i) how contextual differences in the Global North and South may create different work-family issues and raise different questions; (ii) the limitations of Northern conceptualizations, methods and operationalisations in studying work-family interface in the South; and (iii) the differences and similarities within the African continent with respect to work-family issues, policy context, and research.

\section{References}

African Development Bank. (2013). Recognizing Africa's informal sector. Available at http://www.afdb.org/en/blogs/afdb-championing-inclusive-growth-acrossafrica/post/recognizing-africas-informal-sector-11645/ [Accessed 17 November 2015].

African Union. (2012). Draft African Common Position on the Family for the international year of the family $+20 . \quad$ Available at http://www.un.org/esa/socdev/family/docs/egm12/AUCOMMONPOSITIOFAMILY.pdf.

Aycan, Z. (2005). Cross-cultural approaches to work family conflict. Paper presented at the inaugural conference on work and family, Barcelona, Spain July 2005.

Blin, M. (2008). Export-oriented policies, women's work burden and human development in Mauritius. Journal of Southern African Studies, 34(2), 239-253.

Cassirer, N. and Addati, L. (2007). Expanding women's employment opportunities: Informal economy workers and the need for childcare. Geneva: International Labour Organisation, Conditions of Work and Employment programme.

Damon, J. (2010). Demographic changes and social security: challenges and opportunities. Summary report of the International Social Security Association project on "Demographic changes and social security: innovations, good practice solutions and lessons learnt. file:///C:/Users/user/Downloads/2Demography_en\%20(1).pdf [Accessed 03 December 2015].

Dancaster, L. and Baird, M. (2015). Predictors of the adoption of work-care arrangements: A study of South African firms. International Journal of Human Resource Management. DOI:10.1080/09585192.2015.1042898.

Dancaster, L. and Cohen, T. (2015). Leave for fathers in SADC countries. Industrial Law Journal, (36): 2474-2494.

Dancaster, L. (2008). Mom at work. Mail\&Guardian Newspaper, September 12-18 Issue: 24.

Drago, R., \& Kasihain, R. (2003). Mapping the terrain of work/family journals. Journal of Family Issues, 24 (4): 488-512.

Heras, M.L., Chinchilla, N. \& Jimenez, E. (2014). Corporate family responsibility. In In S. Nicklin (Ed.) Family Futures. (Pp. 163-166). Tutor Rose

Heymann, J., Earle, A., and Hanchate, A., 2010. Bringing a global perspective to community, work and family. Community, Work \& Family, 7(2), 247-272.

Hill, E. J., Hawkins, A.J., Märtinson, V. \& Ferris, M. (2003). Studying “working fathers": comparing fathers' and mothers' work-family conflict, fit, and adaptive strategies in a global high-tech 
company. Fathering: A Journal of Theory, Research, and Practice about Men as Fathers, 1(3), 239-261.

International Labour Organisation. (2010). Global employment trends January 2010. Geneva: International Labour Organisation.

Jacobs, J.A. (2013). The work and family researchers network: An organisational and intellectual agenda. Community, Work \& family, 16 (3):226-238.

Korenman, S. \& Kaester, R. (2005). Work-family mis-match and child wellbeing: A review of the economic research. In S.M. Bianchi, L.M. Casper \& R.B. King (Eds.), Work, Family, Health and Wellbeing. (Pp.293-308). Mawah: Lawrence Erlbaum Associates.

Kusakabe, K. (2006). Reconciling work and family: Issues and policies in Thailand. Geneva: International Labour Organisation, Conditions of Work and Employment Series No. 14.

Mapedzahama, V. (2014). Work and family in a cross-cultural context: A comparative review of work-family experiences of working mothers in Australia and Zimbabwe, In Z. Mokomane (Ed.) Work-Family Interface in Sub-Saharan Africa: Challenges and Responses. (Pp. 37-53). New York: Springer Publishing.

Mokomane, Z. (2009). Work-family conflict and gender equality in South Africa. Paper presented at $26^{\text {th }}$ International Population Conference, Marrakech, Morocco, 28 September -2 October 2009.

Mokomane, Z. (2014). Introduction. In Z. Mokomane (Ed.) Work-Family Interface In Sub-Saharan Africa: Challenges And Responses. (Pp. 3-15). New York: Springer Publishing.

Mokomane, Z. and Chilwane, D. (2014). A review of work-family research in sub-Saharan Africa. In Z. Mokomane (Ed.) Work-Family Interface In Sub-Saharan Africa: Challenges And Responses. (Pp. 192-205). New York: Springer Publishing.

Njuguna, F \& Itegi, F. (2013). Research institutions of higher education in Africa: Challenges and prospects. European Scientific Journal. Special edition Vol. 1:352-361.

O'Brien, M. (2012). Work-family balance policies. Background paper prepared for the United Nations Department of Economic and Social Affairs. New York: UNDESA.

Poelmans, S., Spector, P.E. and Cooper, C.L. Allen, T.D., O'Driscoll, M. and Sanchez, J.I. (2003). A cross-national comparative study of work/family demands and resources. International Journal of Cross Cultural Management, 3(3), 275-288.

Shaffer, M. A., Joplin, J. R., and Hsu, Y. S. (2011). Expanding the boundaries of work-family research: A review and agenda for future research. International Journal of Cross Cultural Management, 11(2), 221-268

UNDP (2009). Human Development Report. http://hdr.undp.org/en/humandev. [Accessed 25 November 2014].

Waldfogel, J. and McLanahan, S., 2011. Work and family: Introducing the issue. The Future of Children, 21(2), 3-14.

WIEGO. (2015). WIEGO Annual Report April 2014 - March 2015. Available at http://wiego.org/sites/wiego.org/files/publications/files/WIEGO-Annual-Report-20142015.pdf [Accessed 03 December 2015] 